\title{
Impact of lobster size on selectivity of traps for southern rock lobster (Jasus edwardsii)
}

\author{
S.D. Frusher and J.M. Hoenig
}

\begin{abstract}
Most lobster fisheries are characterized by high exploitation rates. This has led to substantial declines in the size structures of the populations over time as larger lobsters have been removed. Although both scientists and fishers have suggested that size related hierarchies could impact on lobsters entering traps, the effect of the size change on the selectivity of lobster traps as a population's size structure changes has not been investigated. This paper demonstrates that larger lobsters affect the entrapment of smaller lobsters and that this behaviour affects the selectivity of lobster traps. Both spatial and temporal (within season) factors were found to affect the selectivity plots. Spatial differences in selectivity were attributed to the broader size range of larger lobsters found in regions of faster growth. Temporal differences were attributed to the decline in larger lobsters over the course of a season caused by exploitation. There are also differences in trap selectivity between the sexes.
\end{abstract}

\begin{abstract}
Résumé : La plupart des pêches commerciales de Homards ont des taux d'exploitation élevés, ce qui entraîne des déclins importants dans la structure en taille des populations dans le temps, à mesure que les plus grands homards sont retirés. Bien que les scientifiques aussi bien que les pêcheurs aient suggéré que les hiérarchies reliées à la taille pouvaient affecter l'entrée des homards dans les casiers, l'effet du changement de taille sur la sélectivité des casiers à homards, lorsque la structure en taille de la population se modifie, n'a jamais été étudié. Nous démontrons que la présence de plus grands homards affecte la capture des homards plus petits et que ce comportement modifie la sélectivité des casiers. Les courbes de sélectivité sont affectées à la fois par des facteurs spatiaux et des facteurs temporels (intra-saisonniers). Les différences spatiales sont attribuables à l'éventail plus étendu de tailles des plus grands homards dans les régions de croissance rapide. Les différences temporelles s'expliquent par la diminution du nombre de grands homards au cours de la saison à cause de l'exploitation. Il y a aussi des différences de sélectivité des casiers entre les sexes.
\end{abstract}

[Traduit par la Rédaction]

\section{Introduction}

Selectivity is a measure of the catchability of one component of a population (e.g., size class) relative to other components of the population for those animals that encounter a given type of fishing gear. Length-based estimates of fishinggear selectivity are crucial in fisheries science if population parameters are to be estimated from length-structured catch data. Although selectivity of a variety of fishing gears has been estimated, recent papers have demonstrated that selectivity for a particular gear can change both spatially (Anganuzzi et al. 1994; Addison and Lovewell 1991) and temporally (Myers and Hoenig 1997).

Over the last 30 years, the Tasmanian rock lobster (Jasus edwardsii) fishery has sustained a substantial decline in the

Received September 22, 2000. Accepted July 27, 2001.

Published on the NRC Research Press Web site at

http://cjfas.nrc.ca on December 19, 2001.

J15990

S.D. Frusher. ${ }^{1}$ Tasmania Aquaculture and Fisheries Institute, University of Tasmania, G.P.O. Box 252-49, Hobart,

Tasmania 7001, Australia.

J.M. Hoenig. Virginia Institute of Marine Science,

College of William and Mary, P.O. Box 1346,

Gloucester Point, VA 23062, U.S.A.

${ }^{1}$ Corresponding author (e-mail: stewart.frusher@utas.edu.au). biomass of legal-sized animals to a level of approximately $6 \%$ of an unharvested population (Frusher 1997). This has resulted in substantial changes to the size structure of the population, with the bulk of the legal-sized biomass being recently recruited lobsters. Larger lobsters are becoming increasingly rare in the catch (Frusher 1997).

In addition to having a legal-sized biomass based primarily on recruits, the Tasmanian rock lobster fishery has high exploitation rates in most regions (Frusher et al. 1998; Frusher and Hoenig 2001). Within a fishing season there is a substantial shift in the size structure of the population from large (recruited) lobsters to small (undersized) lobsters as large lobsters are harvested.

Most comparisons of the size composition of a population over both spatial and temporal scales assume that selectivity is constant and that the size distributions can be compared directly. Assessment techniques that compare size classes such as the change-in-ratio technique (Pollock and Hoenig 1998; Frusher et al. 1997, 1998) also assume that the selectivity of the size classes being considered does not change between surveys.

Although it is recognized that behavioural changes like those associated with molting affect catchability of lobsters (Morgan 1974; Newman and Pollock 1974; Krouse 1989), behaviour also affects selectivity, as Frusher et al. (1998) found larger lobsters to molt earlier during their molting period. Another factor that could affect selectivity may be the 
presence of size-related dominance hierarchies. Olsen (1958) and Winstanley (1977) suggest that dominant larger-sized lobsters could prevent smaller lobsters from entering traps. Addison (1995) and Miller $(1979,1990)$ suggest that fishing pressure would remove these dominant lobsters and thus influence the size distribution of lobsters entering a trap during the fishing season.

Larger lobsters have been found to have higher catchabilities than smaller lobsters and males to be more "catchable" than females (Miller 1989). Different styles of traps and different areas have also been found to produce different trap selectivity (Addison and Lovewell 1991). However, there have been no studies on the impact on trap selectivity associated with harvest of a population over time.

This paper uses tagging data collected from fisheryindependent catch sampling surveys undertaken from 1992 to 1998 to evaluate temporal and spatial changes in selectivity of rock lobsters in research traps around Tasmania. Tagging data were also obtained from a study of an unfished population in a marine reserve.

\section{Materials and methods}

\section{Reserve sampling}

\section{Site, procedure, and sampling gear}

The Crayfish Point Reserve was established in 1971 and is located in the Derwent estuary in Tasmania (Fig. 1). The reserve extends $800 \mathrm{~m}$ from the shoreline and covers an area of $1.0 \mathrm{~km}^{2}$. Habitat maps of the reserve indicate that approximately $40 \%$ of the reserve is lobster habitat. In 1999, two surveys were undertaken from 28 January to 18 February and from 30 March to 10 April. During each survey, 50 baited lobster research traps were set each day and hauled approximately $24 \mathrm{~h}$ later during the following morning. Traps were set randomly on the lobster habitat and each region of lobster habitat was sampled at least once during each survey. All lobsters caught in each trap were measured to the nearest millimetre of carapace length (CL) and sexed. All lobsters were transported to an adjacent shore-based holding facility at the Tasmanian Aquaculture and Fisheries Institute's marine laboratories. Lobsters greater than $80 \mathrm{~mm}$ CL were tagged ventrally in the flesh of the first abdominal segment (Hallprint T-bar anchor tag; TBA1, Hallprint Pty. Ltd., 27 Jacobsen Crescent, Holden Hill, South Australia 5088, Australia). All lobsters were released back into the reserve at the completion of each survey.

Research traps were similar to the square steel traps that are becoming increasingly popular in southern parts of the fishery and are described in Frusher et al. (1998). The main difference between research traps and commercial traps was that research traps had no escape gaps, which are mandatory for commercial fishing operations. The escape gaps are to allow undersized lobsters to escape without having to be handled during the fishing operation.

\section{Investigating the potential interaction between different sizes in traps}

To investigate whether small lobster catchability was influenced by the presence of larger lobsters, three analyses were undertaken for the reserve data. (i) Catch rates (number of lobsters per trap lift) of small (<90 mm CL) and large lobsters (>140 mm CL) were compared for each day of both surveys. (ii) Correlations between the number of small ( $<90 \mathrm{~mm} \mathrm{CL})$ and large (>109 mm CL) lobsters caught in each trap of both surveys were undertaken. Large lobsters were defined as being greater than $109 \mathrm{~mm} \mathrm{CL}$ for this analysis so that the results could be compared with the regional fishing ground data. Southern regions had no lobsters in the
$>140$ mm CL category. (iii) Selectivity curves based on recaptures of tagged lobsters caught during the first four days and last four days of the second survey were compared.

There were no other reserve areas available to determine if there are any changes in catch rates when lobsters are not removed. However, lobster sampling was identical in surveys undertaken in the reserve in January and December 2000, with the exception that lobsters were released immediately after being measured, sexed, and tagged. We use these surveys to check on the possibility of temporal changes in catch rate occurring independently of removals. Because the data are not bivariate normally distributed, we used Spearman's rank correlation coefficient to test for significance of association.

\section{Estimating selectivity}

Recaptures in the second survey of lobsters tagged in the first survey were used to estimate selectivity. Selectivity could only be determined for male lobsters as female lobsters began to molt between surveys (P. Zeigler, Tasmania Aquaculture and Fisheries Institute, personal communication).

Selectivity $\left(\phi_{l}\right)$ was determined for each $10 \mathrm{~mm}$ CL size class by the proportion of tags returned in the second survey from tagging in the first survey

$$
\phi_{l}=\frac{\left(N_{\mathrm{R} l} / N_{\mathrm{T} l}\right)}{\max _{l}\left(N_{\mathrm{R} l} / N_{\mathrm{T} l}\right)}
$$

where $N_{\mathrm{T} l}$ is the number of lobsters tagged in size class $l$ during the first survey and $N_{\mathrm{R} l}$ is the number of lobsters of size class $l$ tagged in survey 1 that were recaptured in survey 2 . The denominator serves to standardize the selectivity estimates to the interval $(0,1)$. Selectivity was not calculated for size classes where fewer than 20 lobsters were tagged in the first survey.

\section{Research sampling on the fishing grounds}

\section{Sites, procedure, and sampling gear}

Three regions in Tasmania were used to investigate the interaction between different sizes of lobsters caught in traps (Fig. 1). These regions span a range of growth rates from slow growth in the southern region to fast growth in the northern region (Frusher 1997). Only the southern and eastern regions that were sampled from 1992 to 1998 in a fishery-independent catch sampling project were used to determine selectivity in fished regions (Fig. 1). Selectivity could not be determined in the northwestern region because sites were not resampled during each survey and thus there were no recaptures suitable for determining selectivity.

The Tasmanian fishing season opens in November and closes at the end of April and August in the following year for female and male lobsters, respectively. Surveys were undertaken three times each year. A preseason survey was undertaken in October-November, a second survey was conducted in March prior to the female molt (April to May), and the final survey was conducted in July-August prior to the male molt (September to October) (Frusher et al. 1998). On the south and east coasts there are 4 sampling sites and, if weather allowed, we attempted to sample each site twice during each survey. Traps are set randomly within each site, although the sizes of the sites are relatively small $\left(<0.5 \mathrm{~km}^{2}\right)$, thus the majority of lobster habitat is sampled each survey. Each survey consisted of eight and nine overnight fishing shots in the eastern and southern regions, respectively. Each shot involved the setting of 50 identical research lobster traps. Tagging was conducted during each survey. To ensure that the collected data represented the catch from the commercial fishery, sites were selected after consultation with fishers.

Sampling gear was the same as that used in the reserve. From each trap, all lobsters were measured and sexed and in regions where catch rates of lobsters were high, tagging was restricted to 
Fig. 1. Map of Tasmania, Australia, showing the southern, eastern, and northwestern regions surveyed and the location of the Crayfish Point (Taroona) Reserve.

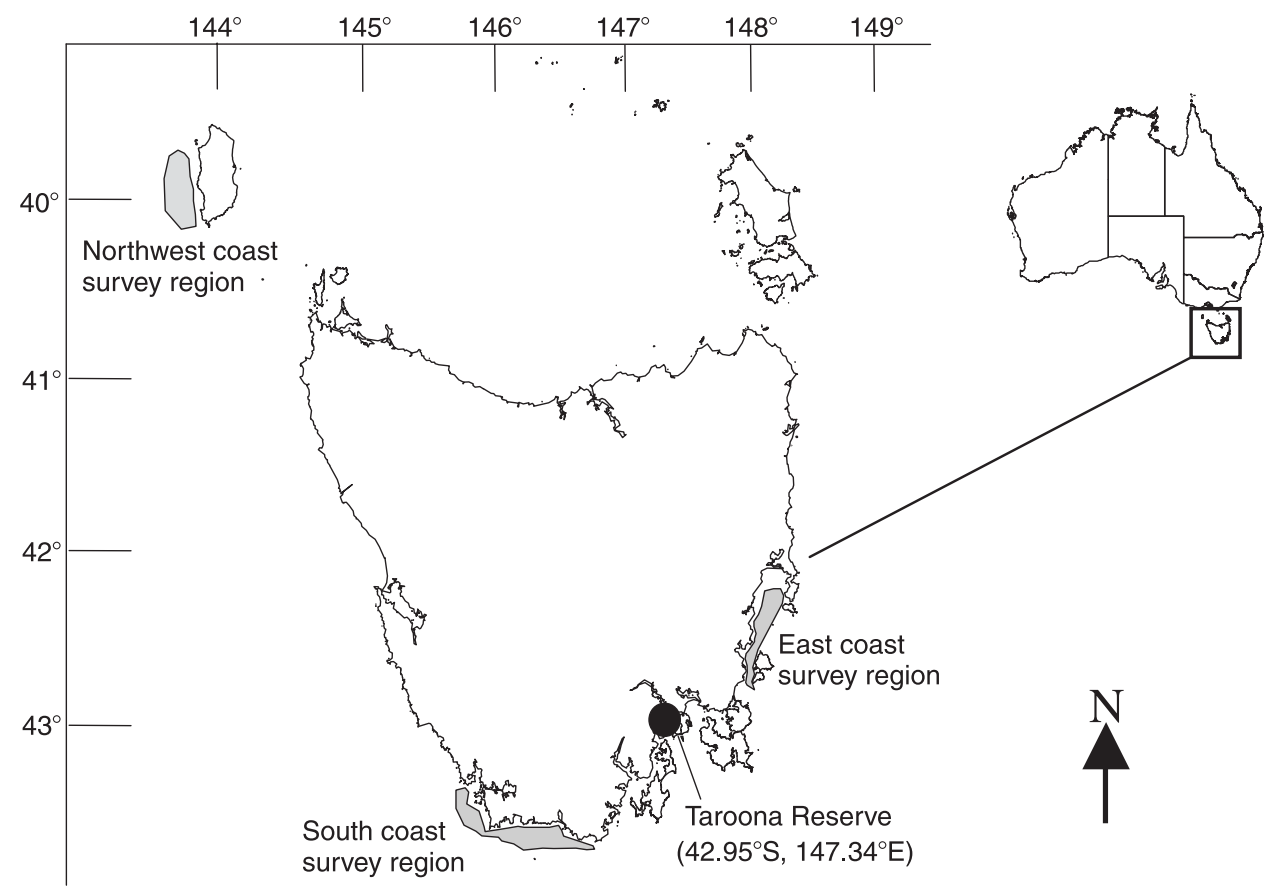

approximately 1000 lobsters per survey This was achieved by tagging the first 200 lobsters per shot. All lobsters (newly tagged, recaptures, and untagged) were released back in their site of capture. Tagging surveys were used to determine selectivity when the difference in the mean of tagged and recaptured lobsters differed by less than $5 \mathrm{~mm} \mathrm{CL}$ and $4 \mathrm{~mm} \mathrm{CL}$ on the east and south coasts, respectively.

\section{Investigating the potential interaction between different sizes in traps}

To investigate whether there was an interaction between the catchability of small and large lobsters, the correlation was estimated for the number of small lobsters ( $<90 \mathrm{~mm} \mathrm{CL})$ and large lobsters (>109 mm CL) caught in individual research traps. As for the reserve data, Spearman's rank correlation coefficient was used to test for significance of association.

\section{Estimating selectivity}

On the commercial fishing grounds, selectivity estimates could only be made from surveys where recaptures were obtained from lobsters tagged during each specific survey (e.g., only recaptures obtained during the March 1994 survey from lobsters tagged during the March 1994 survey could be used). Both molting and harvesting of legal-sized lobsters affected the size distribution of tagged lobsters between surveys.

Selectivity $\left(\phi_{l i}\right)$ was determined for each $5 \mathrm{~mm}$ CL size class by the proportion of tags returned on subsequent days after tagging during each survey

$$
\phi_{l i}=\frac{\left(N_{\mathrm{R} l i} / N_{\mathrm{T} l i}\right)}{\max _{l i}\left(N_{\mathrm{R} l i} / N_{\mathrm{T} l i}\right)}
$$

where $N_{\mathrm{T} l i}$ is the number of tagged lobsters for each size class $l$ during survey $i$ and is derived from

$$
N_{\mathrm{T} l i}=\sum_{j=1}^{J-1} T_{l j}
$$

where $T_{l j}$ is the number of lobsters of length $l$ tagged on day $j$ of survey $i$, and $J$ is the number of days in the survey. $N_{\mathrm{R} l i}$ is the number of recaptured lobsters for each size class $l$ during survey $i$ and is represented by

$$
N_{\mathrm{R} l i}=\sum_{j=2}^{J} R_{l j}
$$

where $R_{l j}$ is the number of lobsters of length $l$ recaptured on day $j$ of survey $i$.

Selectivity was not estimated for size classes where fewer than 20 lobsters were tagged. Multiple recaptures (the same lobster being caught more than once before the end of a sampling trip) were few and classified as a single recapture to minimize "trap happy" behaviour.

The principal aims of the tagging component of the fishery independent study were to obtain growth and movement information and molt frequency to aid in elucidating exploitation rate estimates in the fishery. Unfortunately there was insufficient data to evaluate seasonal selectivity for each year and thus it was necessary to combine all tagging events from the same survey time period (e.g., March) over all years.

On several occasions tagging focused on specific size groups. To estimate selectivity, tagging needs to be random or needs to target the same size classes over all surveys to be summed. To determine if a tagging event could be used in the selectivity study, the mean length of all lobsters caught was compared to the mean length of all lobsters tagged. Selectivity was determined for each sex separately.

\section{Results and discussion}

\section{Interaction between different sizes in traps}

Reserve

A significant negative correlation was found between catches of large and small lobsters in the reserve (Table 1). The cor- 
relations indicate that there is a sex effect, as large females have a higher negative correlation with both small females and small males than large males have with either small females or small males. This is despite males reaching larger sizes than females.

To further explore the impact of large lobsters on catchability of small lobsters, the daily catch rates of small and large lobsters during the reserve surveys were compared (Figs. $2 a$ and $2 b$ ). Large lobsters showed a decline in catch rates as both surveys progressed, whereas small lobsters showed a gradual increase before beginning to decline. This suggests that the presence of large lobsters in traps at the beginning of the survey was preventing small lobsters from entering the traps. As the number of large lobsters decreased owing to their removal from the reserve, the catch rates of small lobsters increased until their numbers started to decline because of depletion from sampling activities.

To determine if the patterns over time of catch by size group might be due to temporal processes occurring independently of removals, we examined the catch composition over time when animals were trapped but immediately returned to the water (Fig. 3). The composition of the catch remained constant over time. This suggests that it is the reduced abundance of large lobsters that causes the catch rate of small lobsters to increase.

\section{Fishing grounds}

A significant negative correlation was also found between the number of small and large lobsters (regardless of sex) caught in traps during surveys of the Tasmanian rock lobster fishing grounds in each of the three regions surveyed (Table 1). With the exception of the correlation between large males and small females on the south coast, all negative correlations increase from southern to northern Tasmania, as does the size range of lobsters caught (Fig. 4). The reason for the high negative correlation for large males and small females in the south is unknown. The trend in the other correlations would suggest a size-related dominance hierarchy. Agonistic interactions between different-sized Homarus americanus have been reported by Schrivener (1971), Miller (1995), and Karnofsky and Price (1989).

Similar to the situation in the reserve, large females from eastern Tasmania had a higher negative correlation with small lobsters of either sex than large males had with small lobsters of either sex. Both the correlations from the three regions of Tasmania and the catch rates obtained from the reserve suggest that the presence of larger lobsters affects the entrapment of smaller lobsters.

\section{Selectivity}

To use tag recapture information to determine selectivity, we assume that the number of tagged lobsters within each length class in the survey area at the time of recapture is directly proportional to the number of tagged lobsters within the same size class that were released during the first survey. Size-dependent effects such as molting, emigration, natural mortality, tag loss, or tag-induced mortality would bias selectivity estimates. Molting between surveys was only found to occur for females in the reserve and female selectivity plots for these data have not been attempted. Pearn (1994) found virtually no migrations of lobsters in southern and
Table 1. Correlation results between small (S, <90 mm carapace length (CL)) and large (L, >109 mm CL) male (M) and female (F) lobsters caught in the southern, eastern, and northern regions of the fishery from 1992 to 1998 and in a reserve in southeastern Tasmania in 1999 (Fig. 1).

\begin{tabular}{llllll}
\hline Region & & LM:SM & LM:SF & LF:SM & LF:SF \\
\hline Southern & & & & & \\
& Correlation & -0.1227 & -0.3426 & -0.0885 & -0.0379 \\
& $P$ value & 0 & 0 & 0 & 0.0165 \\
& $N$ & 4903 & 5179 & 4178 & 3997 \\
Eastern & & & & & \\
& Correlation & -0.3767 & -0.2596 & -0.4560 & -0.3489 \\
& $P$ value & 0 & 0.0001 & 0 & 0 \\
& $N$ & 3111 & 3496 & 2561 & 3083 \\
Northern & & & & & \\
& Correlation & -0.5265 & -0.5290 & -0.6621 & -0.6586 \\
& $P$ value & 0 & 0 & 0 & 0 \\
& $N$ & 4904 & 5180 & 4179 & 3998 \\
Reserve & & & & & \\
& Correlation & -0.2850 & -0.3211 & -0.3983 & -0.4065 \\
& $P$ value & 0 & 0 & 0 & 0 \\
& $N$ & 923 & 944 & 588 & 607 \\
\hline
\end{tabular}

Note: Spearman's rank correlation coefficients are presented followed by their $P$ values. $N$ is the number of pairs used in each correlation.

eastern Tasmania, Treble (1996) found tag loss to be around $1 \%$ for $J$. edwardsii in southern Australia and Kennedy (1992) estimated natural mortality to be $0.1 \cdot$ year $^{-1}$. We found a combination of tag loss, tag-induced mortality, and tag reporting rate to be $0.23 \cdot \mathrm{year}^{-1}$ in northwestern Tasmania (Frusher and Hoenig 2001). The magnitudes of these effects appear to be low over the study period. Thus, it does not appear likely that these effects can vary greatly by size class.

\section{Reserve}

The male selectivity plot for recaptures obtained in survey 2 from lobsters tagged in survey 1 shows a linear increase with size up to $170 \mathrm{~mm} \mathrm{CL}$ (Fig. $5 a$ ). To determine the effect of a size interaction on selectivity, selectivity was estimated for the first and last four days of the second survey period (Fig. 5b). The start of the survey showed a gradual increase in the selectivity plot up to $145 \mathrm{~mm} \mathrm{CL}$, which was followed by a sharp rise to a peak selectivity of very large (170 to $180 \mathrm{~mm} \mathrm{CL}$ ) lobsters. In contrast, the selectivity plot for the latter four days of the survey had increased selectivity of smaller lobsters ( $<120 \mathrm{~mm} \mathrm{CL})$ and peak selectivity in the 140 to $170 \mathrm{~mm} \mathrm{CL}$ range.

\section{Fishing grounds}

Male lobsters caught during surveys on the east coast of Tasmania show an increase in selectivity with size, peaking at the size grouping above the legal size limit of $110 \mathrm{~mm} \mathrm{CL}$ by $5 \mathrm{~mm} \mathrm{CL} \mathrm{(Fig.} \mathrm{6a).}$

The slope of the selectivity plot for the start of the fishing season is less than the middle- and end-of-season plots. At the middle and end of the fishing season there is an increased selectivity for lobsters in the size range from $80 \mathrm{~mm}$ $\mathrm{CL}$ to $110 \mathrm{~mm}$ CL relative to the selectivity at the beginning of the season. The similarity between the middle- and endof-season selectivity plots would be expected, as over $80 \%$ 
Fig. 2. Comparison of catch rates in the reserve for small ( $<90 \mathrm{~mm}$ carapace length (CL), open circles) and large (>140 mm CL, solid circles) lobsters in $(a)$ survey 1 and $(b)$ survey 2 . The polynomial equations describe the catch rate (CR) as a function of the day $(t)$ of the survey. For survey 1, the equations are $\mathrm{CR}=-0.0012 t^{2}-0.0019 t+0.6716\left(R^{2}=0.4303\right)$ for large lobsters and CR $=-0.0028 t^{2}-0.058 t+0.0701\left(R^{2}=\right.$ 0.3531 ) for small lobsters. For survey 2 , the equations are $\mathrm{CR}=$ $-0.0007 t^{2}-0.0383 t+0.6757\left(R^{2}=0.6985\right)$ for large lobsters and $\mathrm{CR}=-0.0089 t^{2}-0.0844 t+0.0096\left(R^{2}=0.3357\right)$ for small lobsters.

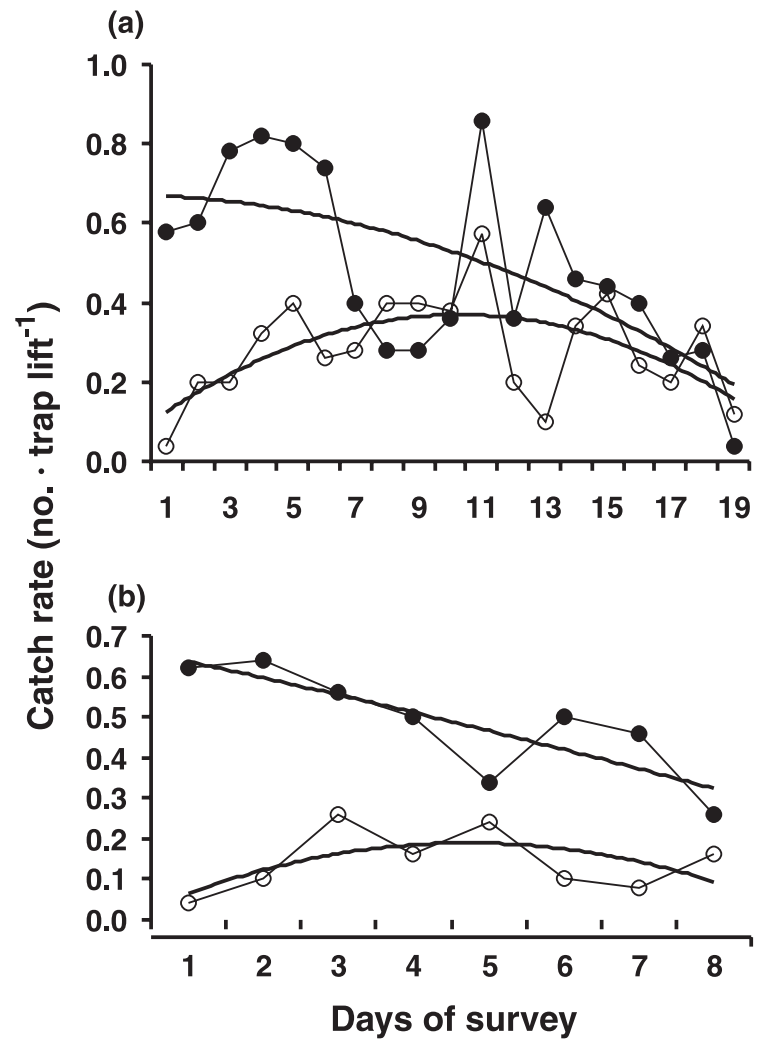

Fig. 3. Proportion of legal-sized male lobsters caught during each day of three surveys undertaken in January 1999 (solid circles) and 2000 (open circles) and December 2000 (open squares). In January 1999 , lobsters were removed from the survey site during the period of the survey. In January and December 2000, lobsters were released into the survey site immediately after capture.

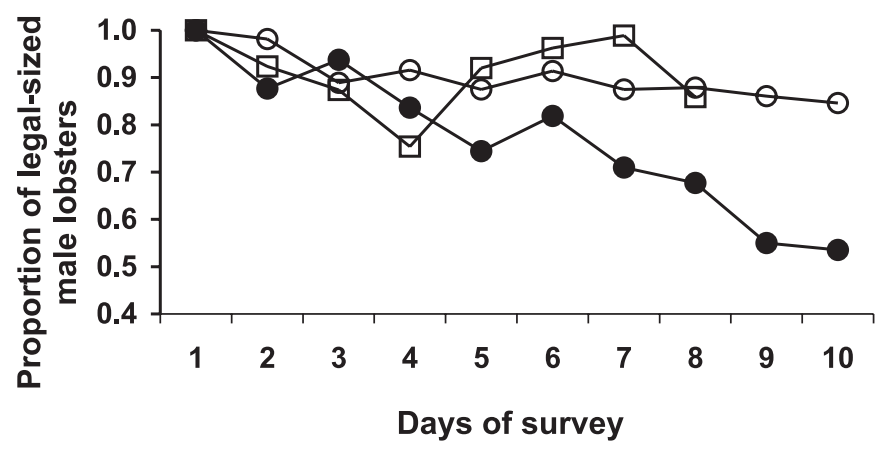

of the commercial catch on the east coast has been taken by the middle survey period (Frusher et al. 1998). This is reflected in the size structure of the population that shows a
Fig. 4. Regional size structure of male lobsters from northern (solid circles), eastern (open circles), and southern (solid squares) Tasmania.

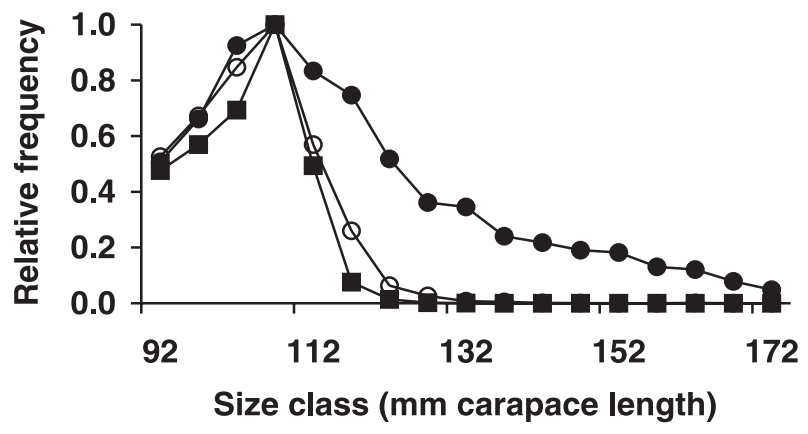

Fig. 5. Estimated selectivity for male lobsters in the reserve for (a) the entire second survey and $(b)$ the first 5 days (solid circles) and last 5 days (open circles) of the second survey. Numbers refer to numbers of recaptures.

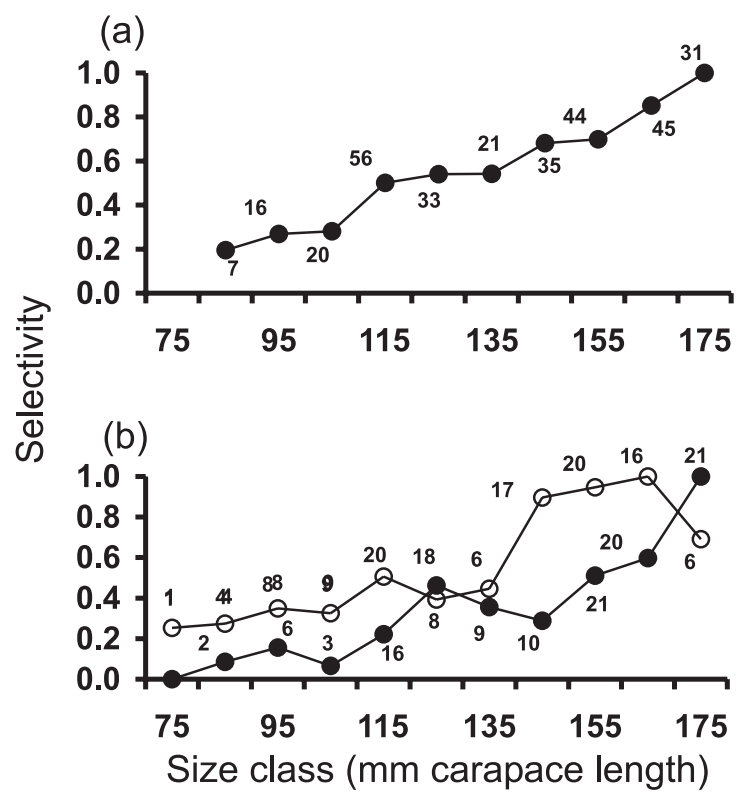

decline in the legal-sized lobsters between the start and middle season and limited change between the middle and end of season (Fig. 7a).

For female lobsters on the east coast, the difference in selectivity plots within a season is less pronounced (Fig. 6b). The start and end-of-season selectivity plots both peak at the 90 to $100 \mathrm{~mm}$ CL interval and are similar in shape except for the 70 to $80 \mathrm{~mm}$ CL interval. The small number of lobsters tagged in this size interval possibly accounts for this discrepancy. The similarity between the plots at the start and end of the fishing season is expected because the commercial season for female lobsters closes after the middle season survey. After this survey, female lobsters molt and thus all legal-sized lobsters for the forthcoming seasons are available for capture during the end-of-season survey. Although the size structures of legal-sized female lobsters at the start and end of the fishing season are not identical (Fig. 7b), they are less different in shape compared to the middle-season size structure. 
Fig. 6. Estimated selectivity for (a) male lobsters from the east coast of Tasmania, $(b)$ female lobsters from the east coast of Tasmania, and (c) male lobsters from the south coast of Tasmania at the start (solid circles), middle (open circles), and end (open squares) of the fishing season.

(a)

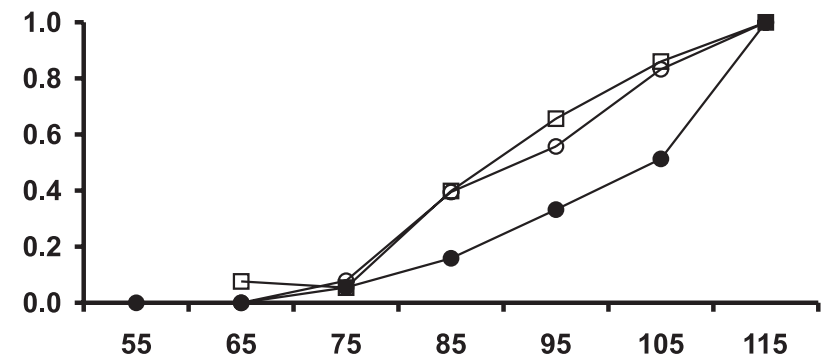

(b)

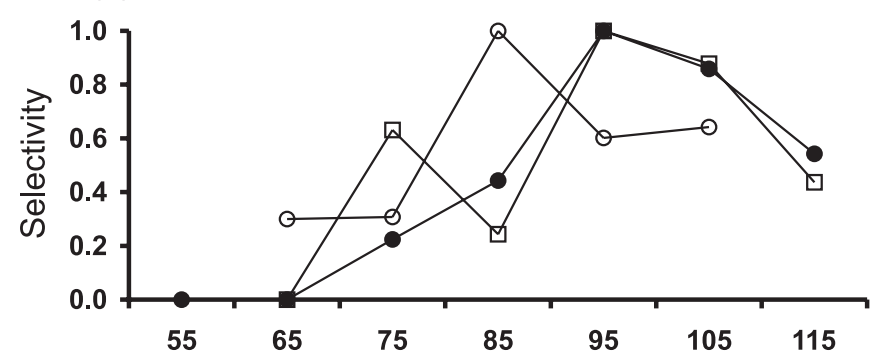

(c)

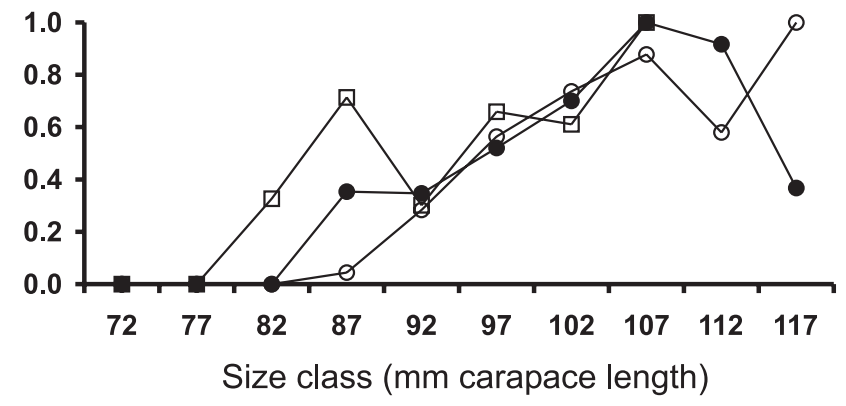

The analysis for the south coast is restricted to males, as females represent less than 5\% of the catch (Frusher 1997). There is very little difference between the selectivity plots for the three survey periods (Fig. 6c). Because of the slow growth and high exploitation in this region there are very few large lobsters. Less than $13 \%$ of the male catch comprised lobsters greater than $140 \mathrm{~mm}$ CL on the south coast, whereas over a third of male lobsters were above this size on the east coast.

\section{Comparison between sexes}

Selectivity of male and female lobsters was compared for the east coast, where there is a high probability of recapturing tagged lobsters of both sexes. To demonstrate the relative differences, the maximum fraction recovered from either sex was used to standardize both plots. In all survey periods, large males had the highest selectivity (Fig. 8). Selectivity for both sexes was similar for lengths up to approximately the 90 to $100 \mathrm{~mm} \mathrm{CL}$ interval (start and end) and the 80 to $90 \mathrm{~mm}$ CL interval (middle). Above these intervals, female selectivity declined, whereas male selectivity continued to increase. This may be related to maturity of females, since
Fig 7. Relative size structure of (a) male lobsters caught in traps on the east coast and $(b)$ female lobsters caught in traps on the east coast at the start (solid circles), middle (open circles), and end (open squares) of the fishing season.

(a)

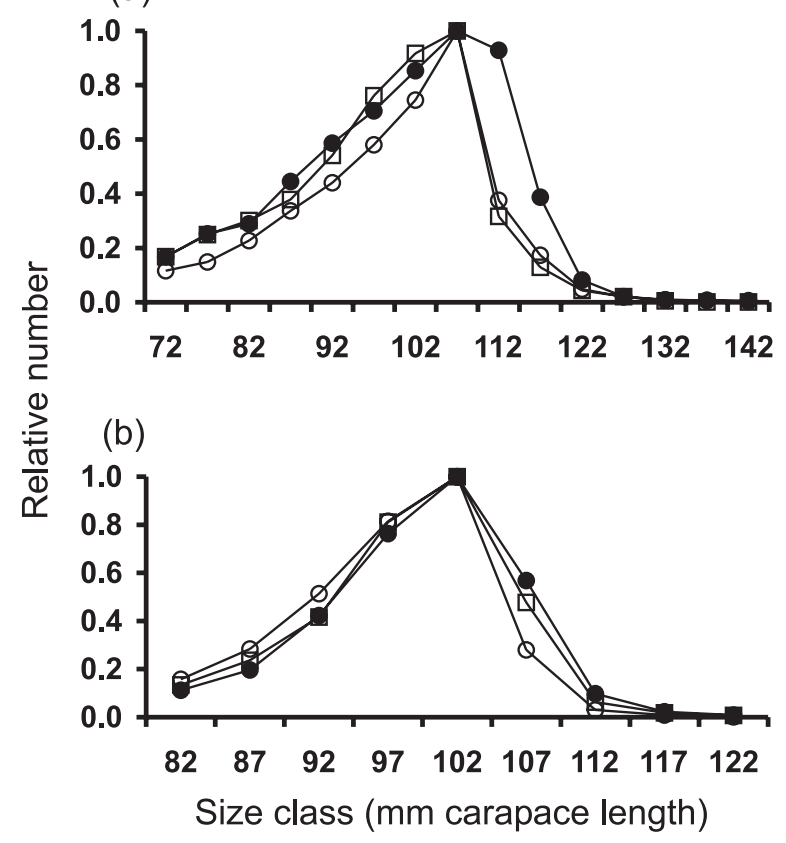

the size at which $50 \%$ of females are mature on the east coast is just below the 80 to $90 \mathrm{~mm} \mathrm{CL}$ interval (Frusher 1997). These results are similar to those reported by Miller (1995), who found the catchabilities of small male and female $H$. americanus to be similar but then to increase more rapidly for males.

\section{Comparison between regions}

Regional comparisons of selectivity can be made between males on the south and east coasts. In all periods within the fishing season, south coast and east coast male selectivity peaked at the size range below and above the legal size limit of $110 \mathrm{~mm} \mathrm{CL}$, respectively (Fig. 9). At the start of the fishing season, undersized males above $80 \mathrm{~mm}$ CL from the south have a higher selectivity than east coast males. As the season progresses, the trends in the selectivity plots become similar.

The correlation data (Table 1) suggested that large males (>109 mm CL) had a larger impact on small males on the east coast compared with the south coast. The regional difference between the selectivity plots at the start of the season is considered to be due to the large males impacting small males, and thus shifting the selectivity plot towards large lobsters. The similarity between the selectivity plots at the end of the season is expected, as the majority of legalsized lobsters ( $\geq 110 \mathrm{~mm} \mathrm{CL}$ ) would be removed by exploitation from both regions.

In conclusion, the above results support fishers' beliefs that large lobsters exclude small lobsters from traps. The correlation data demonstrated that if a large lobster is in a trap it is unlikely that there will be many small lobsters and vice versa. This negative correlation was strongest in regions where large lobsters were abundant. The catch data from the 
Fig. 8. Comparison of selectivity for male (solid circles) and female (open circles) lobsters on the east coast for the $(a)$ start, (b) middle, and $(c)$ end of the fishing season.

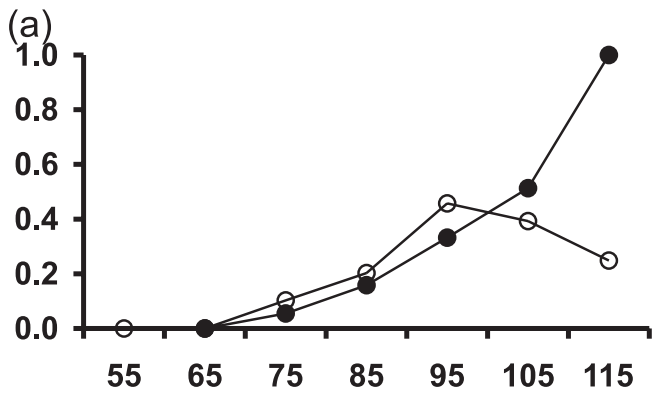

(b)

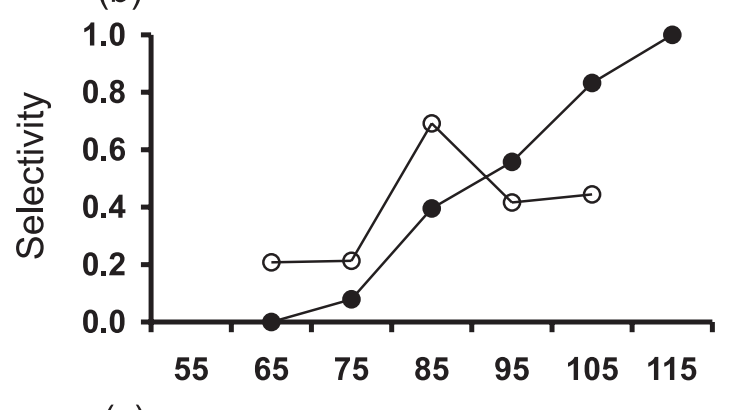

(c)

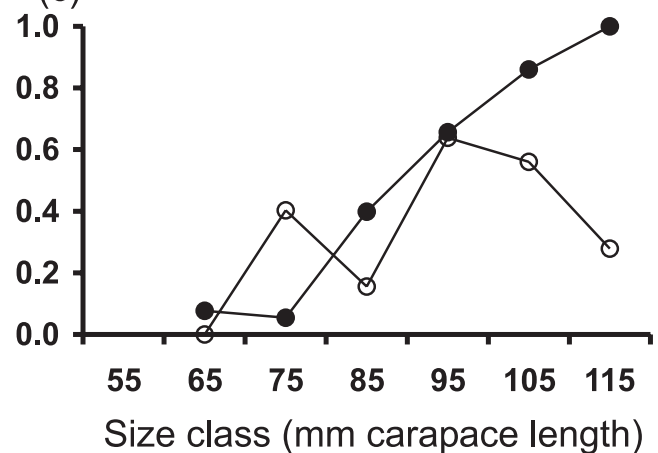

reserve demonstrated that when large lobsters were present, they dominated the catches. As these large lobsters were removed, smaller lobsters became increasingly catchable. This behavioural interaction between small and large lobsters affects the selectivity of the traps. In regions where large lobsters are found, such as the east coast and the reserve in Tasmania, seasonal selectivity plots shift in favour of smaller lobsters as large lobsters are caught. In contrast, the selectivity plots for the southern Tasmanian region showed no differences between the start, middle, and end of season. This was supported by the very low correlation between large and small lobsters and is assumed to be due to the lack of large lobsters in this region. The lack of large lobsters is due to the high exploitation rates (Frusher et al. 1998) and the slow growth (Punt et al. 1997).

The slow growth in the south suggests that it is physical size rather than age that is causing the hierarchical dominance. Owing to their slower growth, lobsters around the minimum legal size limit of $110 \mathrm{~mm}$ CL would be substantially older in southern regions than in more northerly regions. The declining growth rate from northern to southern regions of Tasmania would also increase the age difference
Fig. 9. Comparison of selectivity for male lobsters between the south (solid circles) and east (open circles) coasts for the (a) start, (b) middle, and (c) end of the fishing season.

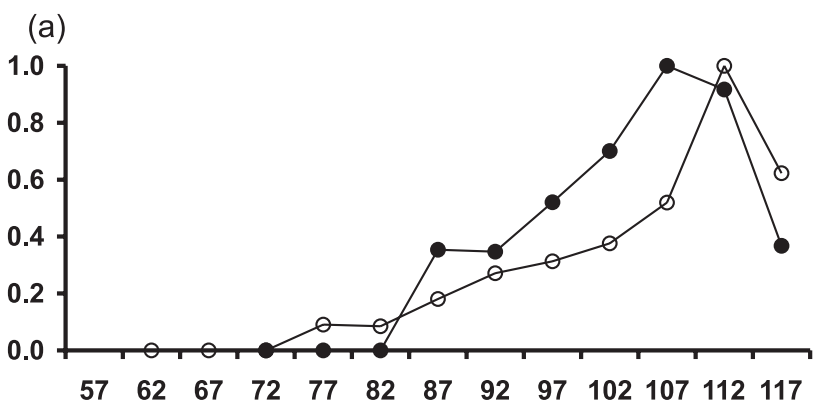

(b)

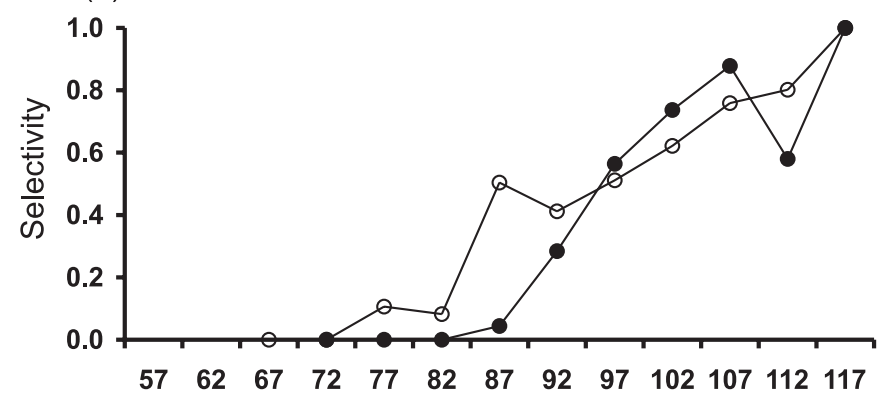

(c)

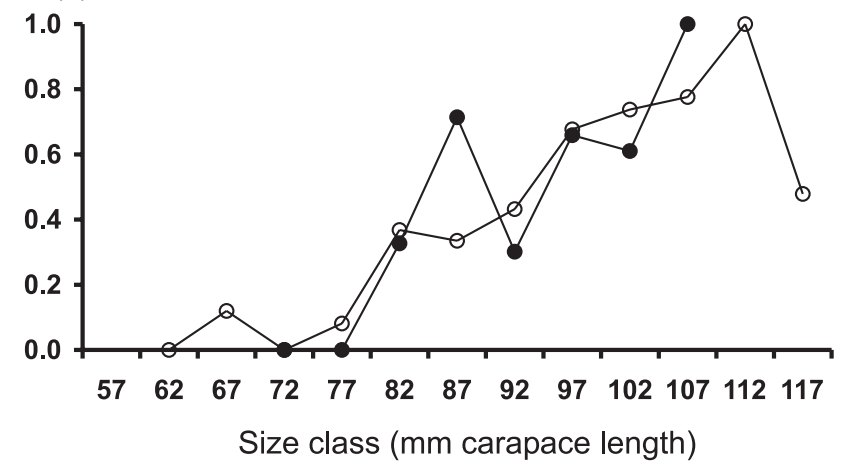

between small (<90 mm CL) and large ( $>109 \mathrm{~mm} \mathrm{CL)}$ lobsters used in the correlation. This further supports the suggestion that it is size rather than an age-related dominance hierarchy.

Although various authors (see Miller 1989, 1995) have found catchability of larger lobsters to be greater than smaller lobsters and that large males have higher catchability than larger females, there has been no exploration of the impact of harvesting on selectivities. This paper demonstrates that selectivity can change with harvesting, even over small time frames such as within a fishing season. Assessment models for lobster fisheries, which use fixed selectivity plots, are likely to overestimate recruitment and this would be compounded over time as legal-sized biomass is fished down. Conversely, these models are likely to under-represent recruitment in fisheries, such as the Tasmanian rock lobster fishery, where management controls are aimed at rebuilding legal-sized biomass. We believe that the impact of varying selectivity on assessment of commercial lobster resources requires further investigation. 


\section{Acknowledgements}

We wish to thank the members of the Crustacean Research Section at the Tasmanian Aquaculture and Fisheries Institute for their efforts during the reserve surveys and the Skipper and Mate of FRV Challenger for providing a safe and pleasant work environment in often difficult weather conditions. We also thank Dr. N. Hall and an anonymous referee for their comments.

\section{References}

Addison, J.T. 1995. Influence of behavioural interactions on lobster distribution and abundance as inferred from pot-caught samples. ICES Mar. Sci. Symp. 199: 294-300.

Addison, J.T., and Lovewell, S.R.J. 1991. Size composition and pot selectivity in the lobster (Homarus gammarus (L.)) and crab (Cancer pagurus L.) fisheries on the east coast of England. ICES J. Mar. Sci. 48: 79-90.

Anganuzzi, A., Hilborn, R., and Skalski, J.R. 1994. Estimation of size selectivity and movement rates from mark-recovery data. Can. J. Fish. Aquat. Sci. 51: 734-742.

Frusher, S.D. 1997. Stock assessment report: rock lobster. Government of Tasmania, Australia, Internal Report No. 35. Tasmanian Department of Primary Industry and Fisheries, Hobart.

Frusher, S.D., and Hoenig, J.M. 2001. Estimating natural and fishing mortality and tag reporting rate of southern rock lobster (Jasus edwardsii) from a multiyear tagging model. Can. J. Fish. Aquat. Sci. 58: 2490-2501.

Frusher, S.D., Kennedy, R.B., and Gibson, I.D. 1997. Precision of exploitation rate estimates in the Tasmanian rock lobster fishery based on change-in-ratio techniques. Mar. Freshw. Res. 48: 1069-1074.

Frusher, S.D., Kennedy, R.B., and Gibson, I.D. 1998. Preliminary estimates of exploitation rates in the Tasmanian rock lobster (Jasus edwardsii) fishery using the change-in-ratio and index removal techniques with tag-recapture data. In Proceedings of the North Pacific symposium on invertebrate stock assessment and management, 6-10 March 1995, Nanaimo, B.C., Canada. Edited by G.S. Jamieson and A. Campbell. Can. Spec. Publ. Fish. Aquat. Sci. 125: 63-71.

Karnofsky, E.B., and Price, H.J. 1989. Behavioural response of the lobster Homarus americanus to traps. Can. J. Fish. Aquat. Sci. 46: $1625-1632$.
Kennedy, R.B. 1992. The biology and fishery for the southern rock lobster Jasus edwardsii in Tasmania: a confidential working document summarizing Tasmanian fishery and the fishery related information which is available within Tasmania. Tasmanian Department of Primary Industry and Fisheries, Hobart.

Krouse, J.S. 1989. Performance and selectivity of trap fisheries for crustaceans. In Marine invertebrate fisheries: their assessment and management. Edited by J.F. Caddy. Wiley, New York. pp. 307-325.

Miller, R.J. 1979. Saturation of crab traps: reduced entry and escapement. J. Cons. Int. Explor. Mer, 38: 338-345.

Miller, R.J. 1989. Catchability of American lobsters (Homarus americanus) and rock crabs (Cancer irroratus) by traps. Can. J. Fish. Aquat. Sci. 46: 1652-1657.

Miller, R.J. 1990. Effectiveness of crab and lobster traps. Can. J. Fish. Aquat. Sci. 47: 1228-1251.

Miller, R.J. 1995. Catchability coefficients for American lobster (Homarus americanus). ICES Mar. Sci. Symp. 199: 349-356.

Morgan, G.R. 1974. Aspects of population dynamics of western rock lobster, Panulirus longipes cygnus George. 2. Seasonal changes in catchability coefficient. Aust. J. Mar. Freshw. Res. 25: 249-259.

Myers, R.A., and Hoenig, J.M. 1997. Direct estimates of gear selectivity from multiple tagging experiments. Can. J. Fish. Aquat. Sci. 54: 1-9.

Newman, G.G., and Pollock, D.E. 1974. Growth of the rock lobster Jasus lalandii and its relationship to the benthos. Mar. Biol. 24: 339-346.

Olsen, A.M. 1958. Inferred size hierarchy in J. lalandei. Fish. Newsl. (Australia), April: 9.

Pearn, R. 1994. Rock lobster tagging shows movement occurs. Fishing Today, 7(5): 27-29.

Pollock, K.H., and Hoenig, J.M. 1998. Change-in-ratio estimators. In Encyclopedia of statistical sciences update. Vol. 2. Edited by S. Kotz, C.B. Read, and D.L. Banks. John Wiley and Sons, Inc., New York. pp. 109-112.

Punt, A.E., Kennedy, R.B., and Frusher, S.D. 1997. Estimating the size-transition matrix for Tasmanian rock lobster Jasus edwardsii. Mar. Freshw. Res. 48: 981-992.

Schrivener, J.C.E. 1971. Agonistic behaviour of the American lobster Homarus americanus (Milne-Edwards). Fish. Res. Board Can. Tech. Rep. 235.

Treble, R.J. 1996. The southern rock lobster (Jasus edwardsii): fisheries biology and abundance estimation. Ph.D. dissertation. University of Melbourne, Australia.

Winstanley, R.H. 1977. Biology of the southern rock lobster. Victorian southern rock lobster fishery seminar, 9-10 June 1997, Portland, Victoria. Commercial Fisheries Section, Fisheries and Wildlife Division, Ministry for Conservation, Victoria, Melbourne. 